\title{
Iris cyst and atypical complications
}

\author{
Cisto de íris e complicações atípicas

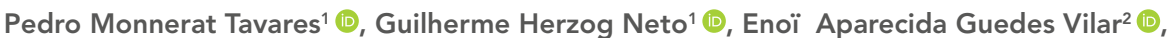 \\ Erika Marques Demori' (D), Marcelo Palis Ventura' ${ }^{1}$ (D), Helena Parente Solari ${ }^{1}$ (1) \\ ${ }_{1}^{1}$ Department of Ophthalmology, Hospital Universitário Antônio Pedro, Universidade Federal Fluminense, Niterói, RJ, Brazil \\ 2Department of Pathology, Hospital Universitário Antônio Pedro, Universidade Federal Fluminense, Niterói, RJ, Brazil.
}

Tavares PM, Herzog Neto G, Vilar EA, Demori EM, Ventura MP, Solari HP. Iris cyst and atypical complications. Rev Bras Oftalmol. 2021;80(3): 00011.

Keywords:

Cysts/pathology; Cysts/ diagnosis; Iris diseases/ pathology; Iris diseases/ diagnosis; Corneal opacity

Descritores:

Cistos/patologia; Cistos/ diagnóstico; Doenças da íris/ patologia; Doenças da íris/ diagnóstico; Opacidade da córnea

Received on: Aug 18, 2020

Accepted on: Mar 31, 2021

Corresponding author: Pedro Monnerat Tavares Rua Manoel Corbal, 10 - Sena Campos. Zip code: 28540-000 - Cordeiro, RJ, Brazil E-mail: cadmonnerat@yahoo.com.br

Instituition: Hospital Universitário Antônio Pedro, Faculdade de Medicina, Universidade Federal Fluminense, Niterói, RJ, Brazil.

Conflict of interest: no conflict of interest.

Financial support: the authors received no financial support for this work.

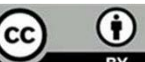

Copyright (C)2021

\section{ABSTRACT}

The authors report the case of a male adult presenting significant ocular complications and irreversible visual impairment, resulting from the long-term progression and late diagnosis of an iris cyst in the right eye, probably secondary to trauma. The patient was admitted to Hospital Universitário Antonio Pedro with a total corneal opacity that blocked direct visualization of the anterior chamber. Ultrasound biomicroscopy was crucial for the anatomic study, and the patient was submitted to enucleation for aesthetic improvement and clarifying diagnosis. We concluded athalamia and deformation of the anterior segment, due to expansion of the cyst, led to gradual elevation of the intraocular pressure and damage of the optic nerve, resulting in visual loss.

\section{RESUMO}

Relatamos o caso de um paciente com evolução e diagnóstico tardios de cisto de íris no olho direito, provavelmente secundário a trauma, com complicações importantes e baixa irreversível da visão, tendo sido admitido no Hospital Universitário Antônio Pedro já com leucoma total da córnea e câmara anterior indevassável. A biomicroscopia ultrassônica se mostrou imprescindível para o estudo anatômico, sendo o paciente finalmente submetido à enucleação, para melhora estética e elucidação diagnóstica. Concluímos que a atalamia e a desestruturação do segmento anterior, consequentes ao crescimento cístico, levaram a um gradativo aumento da pressão intraocular e lesão do nervo óptico, com consequente perda da visão. 


\section{INTRODUCTION}

Iris cysts are probably underdiagnosed and their prevalence underestimated in the general population, due to their indolent and usually silent clinical progression. Nevertheless, with modern diagnostic procedures, such as ultrasound biomicroscopy (UBM) and anterior segment optical coherence tomography, many cases ignored in the past are now detected. ${ }^{(1,2)}$

In 1981, it was proposed that iris cysts should be classified as primary or secondary according to their etiology; as stromal or epithelial with respect to their histologic origin, and further classified as pupillary, midzonal, peripheral, dislodged or free-floating depending on their position in relation to the iris. ${ }^{\left({ }^{3}\right)}$ Among the secondary cysts, we can identify implantation cysts due to surgical or accidental trauma, uveitis, parasitic infections, as well as drug-induced, tumor-induced cysts, or associated with systemic diseases. Of the 3,680 iris tumors described by Shields et al., in 2012, 768 (21\%) were cystic lesions, and the vast majority (85\%) arose from the posterior pigment epithelium of the iris. Primary and peripheral cysts were the most prevalent in this series, and their natural history is probably a long, slow growth that may, in unusual cases, progress to visual loss, uveitis, cataracts, angle closure/glaucoma, and corneal opacity, or even perforation. For secondary cysts, these complications are more prevalent. ${ }^{(2-9)}$

Treatment varies from watchful waiting to more invasive procedures, when eye damage occurs. Most authors agreed that simpler, less invasive procedures, such as fine needle aspiration with or without alcohol, or antimitotic agent infusion into the cyst, cryotherapy, diathermal coagulation and laser (thermal or YAG) are probably warranted..$^{(2,7-9)}$ The objective of this study was to report the case of a male adult presenting significant ocular complications and visual loss, resulting from the long-term progression and late diagnosis of an intraocular iris cyst of the right eye, probably secondary to trauma

This study was approved by the Ethics Committee of Hospital Universitário Antônio Pedro, Faculdade de Medicina da Universidade Federal Fluminense (opinion number 5243), CAAE 06213418.0.0000.5243.

\section{CASE REPORT}

A 54-year-old male patient, builder, who denied previous eye disease or surgery. He was a heavy cigarette smoker but denied any allergies, comorbidities, use of continuous medication, and a family history of neoplasms.. Despite not reporting any specific eye trauma with immediate visual impairment, the patient did not usually wear personal protective glasses during work. Nevertheless, he referred to previous small accidents with ocular foreign bodies, such as sparks and construction dust.

His initial complaint was a protusion in the front of the right eye, with an onset approximately 18 months before, coinciding with visual loss and mild ocular irritation. His symptoms rapidly progressed to corneal opacity and ectasia (Figure 1), after only 15 days of progression, according to the patient. He denied any ocular pain or any topical treatment during this initial phase.

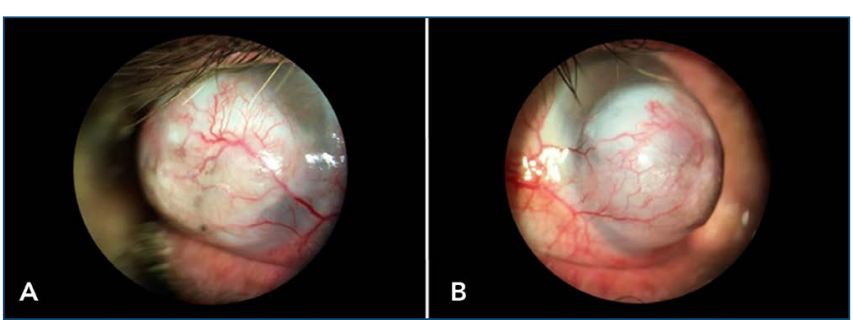

Figure 1. Right eye in right gaze (A) and left gaze (B): total corneal opacity and a vascularized partially translucid lesion, with fibroelastic consistency, measuring the same diameter as the cornea, and slightly elevated $(1 \mathrm{~cm})$, containing areas of central epithelial hypertrophy.

During our investigation, the patient complained of ocular pain, his visual acuity was total blindness in the right eye, and $20 / 25$ best-corrected visual acuity in the left eye. The intraocular pressure (IOP) of the right eye was very high by digital tonometry and $15 \mathrm{mmHg}$ in the left eye. His left eye presented no abnormalities when submitted to a thorough ocular examination (ophthalmoscopy, biomicroscopy, , IOP reading, corneal pachymetry and topography). Routine ocular (B-mode ultrasonography) and lab screening did not elucidate the cause of his ocular disease. A magnetic resonance imaging of the orbit identified a lesion restricted to anterior segment without extraocular extension. Ultrasound biomicroscopy was then deemed necessary, and the procedure revealed multiple cysts and an anechoic lesion that occupied the entire anterior segment of the right eye, hampering iris and ciliary body identification. Multiple synechiae were seen between the ciliary body and posterior cornea, especially at 6 o' clock (Figure 2).

Considering the poor visual prognosis, aesthetic impairment and eye pain, without an established diagnosis for the lesion, right eye enucleation was indicated. Histopathology of the enucleated right eye revealed a chronic non-specific corneal, conjunctival and iris disease process, which induced multiple septum synechiae between the iris, cornea and ciliary body; however, the 


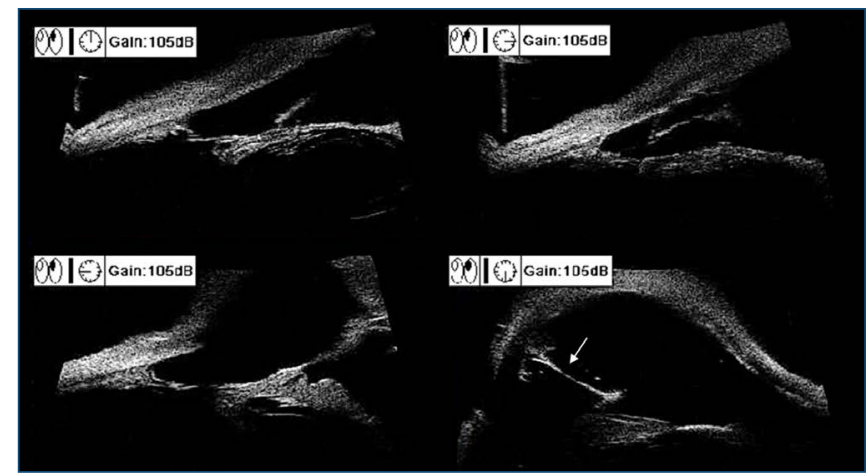

Figure 2. Ultrasound biomicroscopy of the right eye showing anechoic content with multiple cavities on dynamic examination; absence of iris tissue in its physiological topography in all views; the arow indicates synechiae.

ciliary body was preserved (Figure 3). There was a complete attachment between the iris and the posterior cornea, with a slight expansion of the eye and a partial segmental atrophy of the optic nerve (ON) (Figure 4).

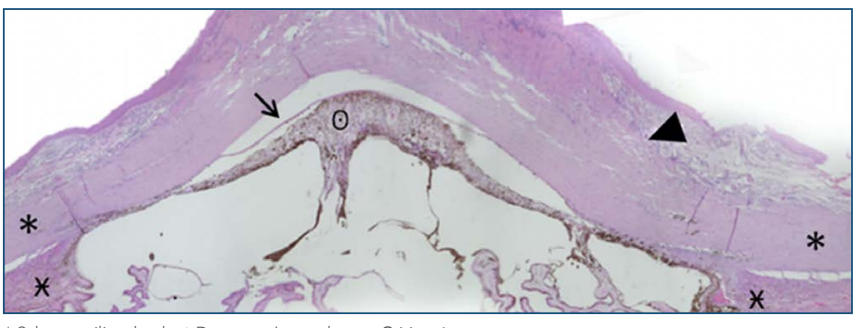

Figure 3. Histopathology: transverse sections demonstrating the adhesions between the structures of the anterior segment, as well as the cystic spaces formed.

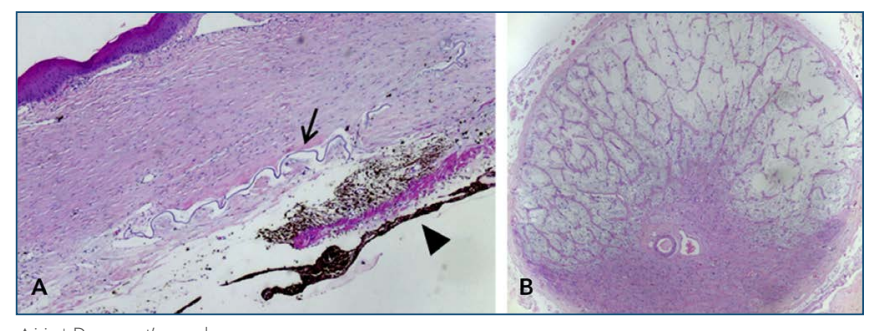

Figure 4. Histopathology of the cornea showing the deformation of its stroma and endothelium, consequent to complete adhesion to the iris tissue (A); a transverse section of the optic nerve in its orbital segment, demonstrating an important atrophy of its upper two-thirds (B).

\section{DISCUSSION}

The understanding of disease process in this patient was hindered by delayed diagnosis and the extreme anatomical deformity induced by intraocular condition. The conclusion of the natural history of this long-standing iris cyst was based on presumptive analysis of the UBM and histopathological report. Although the report classified the lesion as an anterior segment pseudocyst (since no real capsule was seen surrounding the liquid contents of the "bag"), we believe it was a massive implantation cyst, secondary to a trauma ignored by the patient, deforming the anterior structure of the eye.

Although neoplasms of the iris and ciliary body are the most clinically important differential diagnoses, implantation cysts must also be distinguished from epithelial degenerations, endothelial proliferation, iridocorneal endothelial syndrome, and metastases. . $2,3,7-9)^{2}$

However, the histopathological examination revealed an intact ciliary body with a layer of iris pigmentary epithelium covering its entire anterior aspect. The pigmentary epithelium of the iris was also firmly attached to the entire posterior corneal surface, which suggested the origin of the cyst contents (Figure 5). Thus, the chronic and non-specific pattern of the anterior segment inflammation ruled out other possible diseases, such as neoplasms and granulomatous diseases.

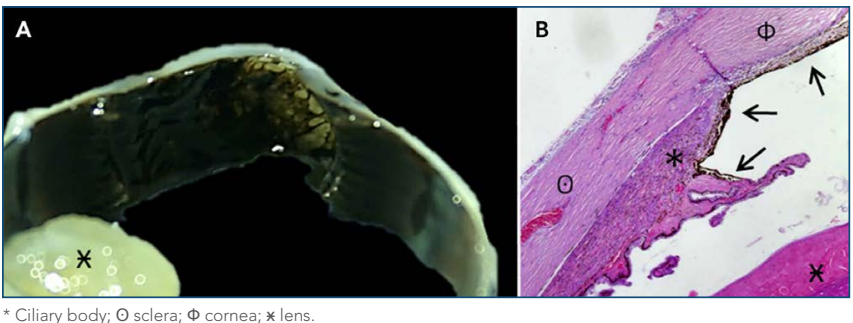

Figure 5. A macroscopic section showing corneal thickening and anterior chamber loss (A); arrows showing the pigment epithelium of the iris covering both surface of the ciliary body and posterior corneal surfaces (B).

Several articles reporting different approaches to treatment of eyes affected with iris cysts take into consideration volume, location, and potential of cysts to cause ocular disease. Haller et al. described various attempted procedures they used to help patients with cystic degenerative eye disease of the anterior chamber. Even though the case reports were not predominantly composed of iris cysts, many different clinical presentations and complications described by the authors exemplified the importance of individualizing treatment of patients. ${ }^{(10)}$

Therefore, we presume the patient had an iris cyst secondary to an ocular trauma, which caused a corneal decompensation due to an iris-corneal touch, angle closure glaucoma and anterior chamber disorder. While the trauma led the onset of corneal decompensation and exuberant leukoma, the increase in IOP resulted in ON atrophy and total visual loss. 


\section{REFERENCES}

1. Ayres B, Allemann N, Nakanami C, Adan CB. Primary cysts of the iris and ciliary body pigment epithelium: ultrasound biomicroscopy features. Arq Bras Oftalmol. 2000;63(5):337-43.

2. Georgalas I, Petrou P, Papaconstantinou D, Brouzas D, Koutsandrea C, Kanakis M. Iris cysts: A comprehensive review on diagnosis and treatment. Surv Ophthalmol. 2018;63(3):347-64.

3. Shields JA. Primary cysts of the iris. Trans Am Ophthalmol Soc. 1981;79:771-809.

4. Xue KC, Hu DD, Zhao L, Li N, Shen HY. Correlation between presence of primary iris and ciliary body cysts and intraocular pressure. Eur Rev Med Pharmacol Sci. 2017; 21(18): 3985-9.

5. Yao Y, Zhang M, Jhanji V. Giant iris cyst with corneal perforation. Optometry Vision Sci. 2015;92(2):e52-4.

6. Schmalfuss TR, Picetti E, Pakter HM. Glaucoma due to ciliary body cysts and pseudoplateau iris: a systematic review of the literature. Arq Bras Oftalmol. 2018;81(3):254-61.

7. Shields CL, Kancherla S, Patel J, Vijayvargiya P, Suriano MM, Kolbus E, et al. Clinical survey of 3680 iris tumors based on patient age at presentation. Ophthalmology. 2012;119(2):407-14.

8. Shields JA, Kline MW, Augsburger JJ. Primary iris cysts: a review of the literature and report of 62 cases. Br J Ophthalmol. 1984;68(3):152-66.

9. Shields CL, Shields PW, Manalac J, Jumroendararasame C, Shields JA. Review of cystic and solid tumors of the iris. Oman J Ophthalmol. 2013;6(3):159-64

10. Haller JA, Stark WJ, Azab A, Thomsen RW, Gottsch JD. Surgical management of anterior chamber epithelial cysts. Am J Ophthalmol. 2003;135(3):309-13. 